1 In situ IR-ATR study of the interaction of nitrogen heteroaromatic

2 compounds with HY zeolites: experimental and theoretical approaches

3

4

5 Ibrahim Khali1 $^{1 *}$, Carlos M. Celis-Cornejo ${ }^{2}$, Karine Thomas ${ }^{1}$, Philippe Bazin ${ }^{1}$, Arnaud Travert ${ }^{1}$,

6 David J. Pérez-Martínez ${ }^{3}$, Víctor G. Baldovino-Medrano ${ }^{2,4}\left(\mathbb{D}\right.$, Jean François Paul ${ }^{5}$, Françoise

$7 \quad$ Maugé 1.

8 ' ${ }^{1}$ Univ. Normandie, UNICAEN, CNRS, Laboratoire Catalyse et Spectrochimie (LCS), F-14050

9 Caen, France.

IR-ATR Infrared Spectroscopy - Attenuated Total Reflectance

DFT Density Functional Theory

DFT-D3 Zero Damping Density Functional Theory Dispersive Correction

FT-IR Fourier Transform Infrared Spectroscopy

IRE Internal Reflection Element

MCT Mercury Cadmium Telluride detector

PAW Projector Augmented Wave Method

PBE Perdew-Burke-Ernzerhof exchange-correlation functional

USY Ultra-Stable Y Zeolite

VASP Vienna Ab-initio Simulation Package

19 


\section{Table of contents}

2

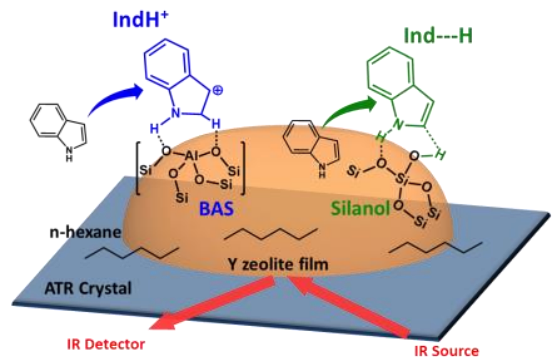

4

5 The interaction modes leading to inhibit the hydrocracking catalysts (e.g. zeolites) by the weakly

6 basic nitrogenates, such as indole, were not yet fully understood. The low vapor pressure of these

7 molecules was presenting the inherent difficulty to their study in the gas phase setups. In this

8 work we evidenced, by combining liquid-solid IR-ATR experiments with Density Functional

9 Theory calculations, the vibrational frequencies of the different interaction modes of pyridine and

10 indole with the zeolitic acid sites.

11 


\section{ABSTRACT}

2 In the present work, the liquid-solid interaction of liquid N-heteroaromatic compounds,

3 commonly present in the petroleum feedstocks of the refineries, with $\mathrm{Y}$ zeolites used in

4 hydrocracking catalysts was followed using IR-ATR spectroscopy. The inhibition of the zeolitic

5 acid sites by strongly basic pyridine as well as by weakly basic indole was highlighted using a

6 continuous flow IR-ATR cell. Results were assessed by Density Functional Theory calculations

7 to compute the vibrational frequencies of pyridine and indole according to the nature of the

8 interaction sites: silanol groups or acidic $\mathrm{OH}$ groups. The study points out that IR-ATR

9 spectroscopy opens the way for investigating the interaction modes of low vapor pressure

10 molecules (e.g. indole) that present an inherent difficulty to be operated in the gas phase.

11 Moreover, the IR-ATR makes possible the analysis of the little-explored low wavenumber zone

$12\left(<800 \mathrm{~cm}^{-1}\right)$, that presents informative vibrational modes on the adsorption mode of $\mathrm{N}$-molecules.

13 Hence, this work points out that for pyridine, the bands at 686 and $727 \mathrm{~cm}^{-1}$ are characteristic of

14 pyridinium species formed over zeolitic $\mathrm{OH}$ groups, meanwhile, the signals at 703 and $750 \mathrm{~cm}^{-1}$,

15 are associated to pyridine in interaction with silanol groups. The IR-ATR study reveals that

16 indole, a weakly basic compound, can be protonated on acidic Y zeolites as unambiguously

17 evidenced by the formation of the bands at 1617, 1608, 1543 and $705 \mathrm{~cm}^{-1}$. Findings here exposed

18 are crucial for studying inhibitory effects exerted by weak nitrogenated compounds on acidic

19 materials during hydrocracking processes.

20 KEYWORDS: IR-ATR in situ, organonitrogen compounds, liquid-solid interface, indole,

21 pyridine, zeolite, Brønsted acidity, silanol group, molecular modeling. 


\section{1. INTRODUCTION}

2 Understanding the adsorption of nitrogen-heteroaromatic compounds over zeolites is a key to

3 improve their design and applications in the chemical industries. ${ }^{[1]}$ The interaction of nitrogen

4 heteroaromatics with zeolites has been amply studied within the frame of refining processes such

5 as hydroprocessing and hydrocracking. ${ }^{[2-6]}$ Among these compounds, pyridine and indole-type

6 molecules are commonly present in the petroleum feedstocks of the refineries. ${ }^{[7]}$ They are

7 recognized to exert inhibitory or poisoning effects over the activity and selectivity of zeolite-

8 based catalysts employed in hydrocracking units. ${ }^{[8-10]}$ The inhibitory effect induced by strongly

9 basic pyridine type compounds; which possess an electron-pair donor ability, is broadly

10 documented. ${ }^{[10-12]}$ Nonetheless, the effect of nitrogen heteroaromatics such as indoles (pKa

11 Indole- $\mathrm{H}^{+} /$Indole $=-3.6$ ), carbazoles, benzocarbazole over hydrocracking catalysts has only been

12 recently put in evidence. ${ }^{[4,9]}$ Indeed, a previous work confirmed that weakly basic nitrogenates are

13 the most abundant nitrogenates in a hydrotreated vacuum gas oil (ca. 20 ppm of total nitrogen

14 content) ${ }^{[4]}$ Even at such a low concentration level, these compounds reduced the catalytic activity

15 and influenced the selectivity of the employed catalyst. ${ }^{[4]}$ However, the interaction mode leading

16 to inhibit the zeolitic acid sites by the weakly basic nitrogenates was not fully understood.

17 Otherwise, $\mathrm{N}$-heteroaromatic compounds such as indole are also valorized in the synthesis of fine chemical (pharmaceuticals, agrochemicals, and dyes). ${ }^{[13-20]}$ These reactions are conventionally performed over both liquid phase Brønsted acids and Lewis acids. ${ }^{[1]}$ However, due to the production of harmful wastes, corrosion issues, and the difficulty of product separation, recent efforts have been made in replacing these substances by zeolites. ${ }^{[19,20]}$ Indeed, the reaction of indole with zeolitic acid sites was reported for the production of biologically and physiologically active chemicals, by electrophilic or nucleophilic substitutions reactions. ${ }^{[22]}$ Gopal et al. studied the vapor-phase alkylation of indole with methanol to produce 3-methylindole over a series of protonic and rare earth cation exchanged Y zeolites and HZSM-5 zeolites. ${ }^{[19]}$ The authors reported that the Brønsted and Lewis acid sites of medium strength are key for the performed reaction. 
1 with aldehydes, using proton exchanged $\mathrm{H} \beta, \mathrm{HY}, \mathrm{HZSM}-5$, and Zn ion-exchanged Y zeolites, for

2 producing bis(indolyl)methanes; that are active substances for the promotion of beneficial

3 estrogen metabolism in the human body. ${ }^{[20]}$ The authors claimed a correlation between the

4 increases of the reaction yield and the amount of Lewis acid sites, assessed by DRIFT

5 measurements of adsorbed pyridine. However, the interaction mode of indole molecules with the

6 active sites in the zeolites was not investigated.

7 In this sense, IR spectroscopy can be used to discriminate the different interaction modes of the 8 molecules with the acid sites of the catalysts. ${ }^{[23]}$ Most of the work, in which IR spectroscopy 9 characterizations are included, make use of the transmission-adsorption and diffusive reflectance 10 mode of analysis. ${ }^{[24]}$ Thus, IR cells for in situ and operando studies working on transmission mode 11 have been developed for characterizing the different interaction modes of the molecules with the acid sites after specific activation conditions and/or during the reaction. ${ }^{[23]}$ The feasibility of an IR gas phase study is limited by the vapor pressure of the studied probe molecules. For pyridine, the saturation of solid materials under low pressure conditions is relatively easy to perform since the vapor pressure of the molecule is about $2733 \mathrm{~Pa}$ at $298 \mathrm{~K} .{ }^{[25]}$ However, when the molecules exhibit low vapor pressures, such as indole and indole-derivatives $\left(P_{\text {indole }}^{\text {sat }}=1.6 \mathrm{~Pa}\right.$ at $\left.298 \mathrm{~K}\right)$, their handling in the IR in situ cell becomes either problematic or unfeasible. In such cases, the characterization with IR-ATR spectroscopy opened a wide range of possibilities for in situ studies of liquid-solid adsorption. ${ }^{[26]}$ Experimental setups concerning IR-ATR continuous flow, ${ }^{[27-29]}$ batch cells, ${ }^{[30]}$ and others have been adapted for studying the adsorption of probe molecules in the liquid phase, ${ }^{[26]}$ as well as for homogeneous and heterogeneous catalytic processes and electrochemical studies. ${ }^{[31-38]}$ In particular, Rivera et al. performed pyridine adsorption in liquid phase over sol-gel films deposited over the ATR crystal solubilized in n-heptane and methanol. ${ }^{[27]}$ Panella et al. used a liquid-solid IR-ATR batch cell to study the reactivity of amino-functionalized silica-coated magnetic nanoparticles of $\mathrm{SiO}_{2} / \mathrm{Fe}_{3} \mathrm{O}_{4}{ }^{[30]}$

As a complement to IR spectroscopy experiments, first-principle calculations for the adsorption of probe molecules can provide deeper insights into the mechanisms of adsorption. Figure SI-1 
1 depicts the formation of the ion-pair complex for pyridine adsorbed on a model Brønsted site. ${ }^{[39-}$

$2 \quad{ }^{41]}$ In this sense, Castellà-Ventura et al. described the vibrational modes of pyridine adsorbed on 3 a twelve tetrahedra (12T) cyclic cluster, for modeling the zeolite acid site. ${ }^{[42]}$ The authors drew 4 attention to the importance of including dispersive interactions in the quantum mechanical model 5 for future studies. Their results were in line with the formation of an ion-pair complex of pyridine 6 H-bonded to the acid site, concluding that the mentioned adsorption mode is energetically more 7 stable than the non-protonated hydrogen-bonded pyridine molecule. Thus, the interest of the 8 theoretical assessment for predicting the characteristic bands in the IR spectrum for a specific 9 interaction of probe molecules was clearly shown. We should mention here that the literature does not report any study of the adsorption of indole molecules on acidic solids.

11 Given the foregoing, in this work, an assessment of the adsorption of pyridine and indole on zeolites via an in situ liquid-solid IR-ATR methodology is presented. Two zeolites presenting different $\mathrm{Si} / \mathrm{Al}$ ratios were studied: namely, HY and USY. Besides, siliceous MCM-41 was also used as a material free of aluminum and with very limited acidic properties. Experiments were complemented by DFT calculations to help in the interpretation of the results.

In the first part of the study, the validation of the IR-ATR liquid system was successfully performed by comparing pyridine adsorption in the gas and liquid phases over different solids. The bands relative to the different adsorption modes of pyridine, e.g. over Brønsted acid sites, silanol groups, and Lewis acid sites were distinguished from the characteristic bands belonging to pyridine in the liquid phase. In the second part, the adsorption and protonation of liquid indole, an unfeasible experiment in the IR gas setups, was successfully carried out in the IR-ATR liquidsolid setup. IR-ATR allows also exploring the low wavenumber zone $\left(<800 \mathrm{~cm}^{-1}\right)$ which is generally opaque in classical IR gas analyses, mainly due to the presence of structural vibrations of the studied materials. Combining experiments and DFT calculations provided evidence for the protonation of indole. Thus, the obtained results confirm that the weakly basic nitrogenates such as indole may strongly interact with zeolitic Brønsted acid sites, which explains the inhibitory effect on acid-type reactions reported on zeolite catalysts. ${ }^{[4,9]}$ 


\section{2. EXPERIMENTAL SECTION}

2

3

4

5

6

7

8

9

\subsection{Studied Materials}

Three solids were studied: namely, proton exchanged $\mathrm{HY}$ zeolite, $\mathrm{Si} / \mathrm{Al}=2.5$, ultra-stable $\mathrm{Y}$ (USY) zeolite, Si/Al = 33, and a siliceous MCM-41. HY zeolite and H-USY were supplied by

Union Carbide and Zeolyst International, respectively. Both zeolites were used as provided by 6 the suppliers. MCM-41 was prepared using the procedure of Grün et al., as described in Supporting Information (SI). ${ }^{[43]}$

\subsection{Assessment of Physicochemical Properties}

Chemical composition. The silicon and aluminum contents of the zeolites were measured by inductively coupled plasma (ICP) coupled with optical emission spectroscopy using a Varian ICPOES 720-ES. ca. $50 \mathrm{mg}$ of the solid to analyze was first dissolved in $1 \mathrm{ml}$ of aqua regia $\left(\mathrm{HNO}_{3} /\right.$ $\mathrm{HCl}=1 / 3 \mathrm{v} / \mathrm{v}$ ) and $3 \mathrm{ml}$ of hydrofluoric acid (Merck, $\geq 48 \%$ in water). After $1 \mathrm{~h}$ of stirring at $383 \mathrm{~K}, 20 \mathrm{ml}$ of ultra-pure water (VWR, > 99.99\%) and $3.6 \mathrm{~g}$ of boric acid (Merck, $\geq 99.5 \%$ ) were added. Finally, the solution was diluted until reaching a total volume of $100 \mathrm{ml}$. The concentrations of Si and Al obtained from ICP-OES are shown in Table 1.

Porosity and surface area. The porosity and surface area of the solids were estimated from nitrogen adsorption-desorption isotherms measured at 77K using an ASAP 2020 (Micrometrics) gas adsorption system within a relative pressure $\left(\mathrm{P} / \mathrm{P}_{0}\right)$ range between 0.05 and 1.00 . Before the adsorption of nitrogen, samples of ca. $100 \mathrm{~g}$ were outgassed at $623 \mathrm{~K}$ under vacuum for $4 \mathrm{~h}$. The total and external surface areas were determined based on the BET theory for the zeolite samples and on the $\alpha$-plot method for the mesoporous silica solids, ${ }^{[44,45]}$ using non-porous silica LiChrospher Si-1000 (surface area $\left.=26.2 \mathrm{~m}^{2} \cdot \mathrm{g}^{-1}\right)$ as a reference. The corresponding isotherms are shown in supporting information (Figure SI-2).

IR study of the gas probes over the solids. The evaluation of the acidity of the solids was performed by gas-phase pyridine adsorption followed by Fourier Transform Infrared (FT-IR) 
1 spectroscopy. Samples were pressed into self-supported wafer (10 - $15 \mathrm{mg}$, precisely weighted) with a surface of $2.0 \mathrm{~cm}^{2}$ under a pressure of $\sim 10^{7} \mathrm{~Pa}$ using a Specac press. These wafers were in situ activated under secondary vacuum from $298 \mathrm{~K}$ to $623 \mathrm{~K}\left(1 \mathrm{~K} \cdot \mathrm{min}^{-1}\right)$ and kept under the latter temperature for $4 \mathrm{~h}$ under $10^{-4} \mathrm{~Pa}$. FT-IR spectra were recorded after submitting wafers to the latter treatment. The vapor of pyridine was introduced into the cell at $298 \mathrm{~K}$ and dosed from 0.09 to $0.90 \mu \mathrm{mol}$. A final equilibrium pressure of $266 \mathrm{~Pa}$ was established in the IR cell. Desorption was carried under secondary vacuum $\left(10^{-4} \mathrm{~Pa}\right)$ at different steps of temperature until $423 \mathrm{~K}$ for 20 min in each step. FT-IR spectra were recorded with a Thermo Fischer 6700 instrument equipped with an MCT detector. 64 scans were accumulated for each measurement with a resolution of 4 $\mathrm{cm}^{-1}$. Spectra were analyzed by subtracting spectra collected after adsorption (or desorption) from the spectra corresponding to the activated samples. All spectra were normalized to a disc constant mass of $5.0 \mathrm{mg} . \mathrm{cm}^{-2}$ of the dried solids. The amount of acid sites was calculated by integrating the bands related to the residual pyridinium ions (Brønsted sites) and coordinated pyridine species (Lewis sites) after desorption and considering their molar absorption coefficients. ${ }^{[46]}$

\subsection{IR-ATR Study of the Liquid Probes over the different Materials}

The adsorption of solutions of n-hexane with pyridine (1 wt.\%) or indole $(0.5 \mathrm{wt} . \%)$ over the different zeolites and MCM-41 films was studied by in situ IR-ATR measurements.

The schematics of the home-built continuous flow IR-ATR setup are shown in Figure 1. The cell consists of a dome-like device mounted on the IR-ATR crystal that allows the flow of either gases or liquids streams by a 3-ways valve. The Internal Reflection Element (IRE) was provided with a Specac Golden Gate ATR device along with a diamond crystal and one reflection beam. The IRE was placed in a Nicolet iS50 FTIR spectrometer equipped with nitrogen cooled MCT detector and purged under a flow of dry air without $\mathrm{CO}_{2}$. Two recipients, one containing the solution with pyridine or indole and another containing the pure solvent were connected simultaneously to a multi-channel peristaltic pump (Ismatec). An additional 3-ways valve was employed for switching from the flow of the solution to the solvent. The solvent employed was n-hexane (99\%, Sigma-Aldrich), and the test solutions contained $1 \mathrm{wt.} \%$ of pyridine (99.9\%, Merck) or $0.5 \mathrm{wt} . \%$ 
1 of indole (>99\%, Sigma-Aldrich). The indole solution was less concentrated due to the low

2 solubility of this compound in non-polar solvents. Finally, a recipient was employed for storing

3 the liquid effluents at the outlet of the IR-ATR cell.

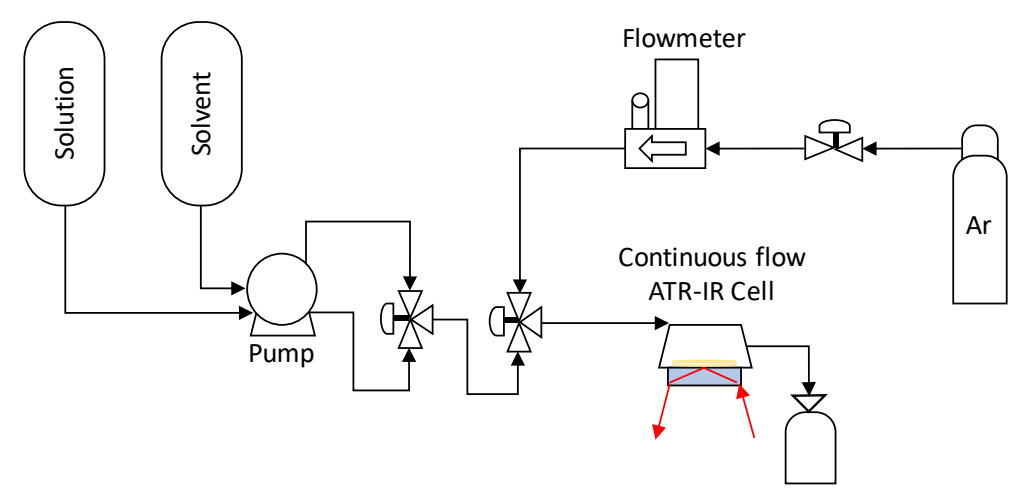

Figure 1. Flowsheet type scheme of the continuous flow IR-ATR cell setup. The solution recipient contains the diluted $\mathrm{N}$-molecule into n-hexane; the solvent recipient contains pure n-hexane.

4 Prior to adsorption tests, a background was always recorded with the empty cell under an Argon

5 flow of $50 \mathrm{ml} \cdot \mathrm{min}^{-1}$. Each spectrum corresponds to the average of 32 scans collected with a

6 resolution of $4 \mathrm{~cm}^{-1}$ (time resolution $\sim 20$ seconds). Spectra from the liquid solution and the solvent

7 were recorded. The samples of the zeolites were pretreated ex situ at $623 \mathrm{~K}$ for $4 \mathrm{~h}$ under secondary vacuum $\left(10^{-4} \mathrm{~Pa}\right)$. The method proposed by Davantès et al. was adapted to deposit the solid film of the sample onto the ATR crystal. ${ }^{[28]}$ Accordingly, a droplet of the concentrated suspension of the pretreated solid, with a granulometry less than $20 \mu \mathrm{m}$, was put on top of the IR-ATR crystal and left to dry. Thereafter, the deposited zeolites were dehydrated in situ under an argon flow of $30 \mathrm{ml} . \mathrm{min}^{-1}$ at $473 \mathrm{~K}$ for $4 \mathrm{~h}$. The MCM-41 film was studied without in situ activation because of its instability during the treatment. After activation, the system was cooled down to RT, and an n-hexane flow was put in contact with the solid sample, we should mention that, in this step, all the solid films fairly resisted the sheer tension of the liquid flow. From this point onwards, a loop for the acquisition of IR-ATR spectra every $20 \mathrm{~s}$ was used to follow the accumulation of n-hexane. The spectrum corresponding to saturation of the solid film by n-hexane was taken as a reference to perform further difference with the spectra corresponding to adsorption of the nitrogen aromatic compounds in solution with n-hexane on the solid film. Afterward, keeping the same flow rate, the flow was switched to the solution containing pyridine or indole until reaching saturation. 
1 Finally, the desorption of the weakly or non-adsorbed probe molecules was achieved by switching

2 back the liquid flow to $n$-hexane for several minutes.

\subsection{DFT Calculation of the Frequencies of Organonitrogen Compounds on}

\section{Protonic sites}

The molecular level adsorption of the nitrogen heterocycles was assessed by theoretical DFT calculations performed on a Brønsted acid site located at the pore mouth of a model mordenite. ${ }^{[47]}$ Mordenite was chosen instead of faujasite to save computational resources, because of the considerably reduced number of atoms in the conventional unit cell of the latter; 144 atoms for mordenite in comparison to 576 atoms for faujasite, if we compare the pure siliceous structures. In addition, the modeling was a constraint to the adsorption of the organonitrogen compounds on the pore mouth of mordenite. In this regard, the choice of mordenite, which has a $12 \mathrm{~T}$ main cavity as in the supercage of faujasite, should not significantly affect the calculated vibrational frequencies. Such an assumption is based on a theoretical finding that evidenced that the stretching mode of the $\mathrm{O}-\mathrm{H}$ group of Brønsted acid sites is not significantly affected by the position of the aluminum atom in the different cavities of the framework. ${ }^{[48]}$ Additionally, the IR spectra of pyridine adsorption on different Y-zeolites and mordenite showed the characteristic bands of pyridine almost at the same frequency values. ${ }^{[49]}$ It was also shown that the strength in the acidity, which is well described by the adsorption energy of electron donor basic molecules, is more related to the chemical composition of the zeolite than to its morphology. ${ }^{[50]}$

Calculations were carried out using the Vienna Ab-initio Simulation Package (VASP) considering periodic boundary conditions and pseudo potentials. ${ }^{[51-53]}$ The Projected Augmented Wave (PAW) method and the Perdew-Burke-Ernzerhof (PBE) exchange-correlation functional were chosen for performing all the calculations. ${ }^{[54-56]}$ An energy cut-off of $600 \mathrm{eV}$ was set with a $\Gamma$ point for sampling the Brillouin-zone. Gaussian smearing with a sigma parameter of 0.05 was chosen. Grimme's density functional dispersive correction with zero dampings (DFT-D3) was included to account for dispersive interactions. ${ }^{[57,58]}$ The external surface of the (001) plane of a mordenite zeolite was modeled following the procedure described in previous work. ${ }^{[59]}$ The 
1 Brønsted acid site at the pore mouth was simulated by replacing one silicon atom for an aluminum

2 one, and subsequently hydrogenating the adjacent oxygen atom for compensating the charge. The

3 T2 position of the Brønsted acid site on the twelve tetrahedra principal cavity was chosen

4 following Demuth et al. assumption that this represents the most stable configuration. ${ }^{[60]}$ Terminal

5 silanol groups were created when completing with hydrogen atoms the dandling oxygen atoms

6 bonds that are generated when the 001 plane is cut. A vacuum of $10 \AA$ in the $\mathrm{z}$-axis is added. The

7 optimized 193-atom structure of the external surface of mordenite is shown in supplementary

8 information (Figure SI-3). The acidic characteristics of the modeled Brønsted site in the pore

9 mouth of the mordenite were validated in previous work, ${ }^{[59]}$ calculating the vibrational frequency

10 of the $\mathrm{O}-\mathrm{H}$ group adjacent to the aluminum atom, and the atomic charge of the hydrogen atom. A

11 charge of +0.65 and a frequency of $3604 \pm 5 \mathrm{~cm}^{-1}$ was taken to represent the characteristics of a

12 Brønsted acid site. ${ }^{[48,61]}$

13 For studying the adsorption of the probe molecules, pyridine and indole were first optimized in a

14 vacuum cube box with an edge length of $25 \AA$ and a frequency calculation was subsequently

15 performed for obtaining the data of the isolated gas-phase molecules. The predicted vibrational

16 frequencies (not scaled) for pyridine and indole in the gas phase, interacting with the silanol

17 groups or with protonated $\mathrm{OH}$ groups of the zeolite were calculated. The interaction of pyridine

18 and indole over a Lewis acid site was not computed in this work. The protonation of indole was

19 performed over the carbon in the position 3 of the molecule (C3 site), known and checked to be

20 the site with the highest proton affinity (PA) from all the 7 sites where the protonation is possible

$21 \quad\left(\mathrm{PA}_{(\mathrm{C} 3 \text { protonation })}=212.4 \mathrm{kcal} / \mathrm{mol}\right){ }^{[62]}$

\section{RESULTS AND DISCUSSION}

\section{$23 \quad 3.1 \quad$ Chemical and Textural Properties of the Solids}

24 Table 1 presents the chemical composition and textural properties of the different materials. From

25 ICP results, the $\mathrm{Si} / \mathrm{Al}$ ratio of the zeolites were calculated. An increase in the $\mathrm{Si} / \mathrm{Al}$ ratio for the

26 zeolite USY33 containing less aluminum than HY2.5 is observed. The mesoporous volume of the 
1 USY zeolite is higher in comparison to the HY2.5 zeolite due to the partial destruction of the

2 structure during the aluminum extraction procedure performed by the supplier. The measured

3 chemical and textural properties of the zeolites are similar to the characterization results obtained

4 for these materials in the literature. ${ }^{[63-66]}$ The MCM-41 solid did not present any microporosity as

5 shown in Table 1 and Figure SI-2 (nitrogen sorption isotherms), also the obtained surface area,

6 calculated using the $\alpha$-plot method, was around $1000 \mathrm{~m}^{2} \cdot \mathrm{g}^{-1}$ which is in a good agreement with

7 the results shown by Grün et al. ${ }^{[43]}$

Table 1. Chemical composition and textural properties of the different materials

\begin{tabular}{|c|c|c|c|c|c|c|}
\hline \multirow{2}{*}{ Adsorbents } & \multicolumn{2}{|c|}{ ICP results $\left(\mathrm{mg} \cdot \mathrm{g}^{-1}\right)$} & \multirow{2}{*}{$\begin{array}{c}\text { Surface area }{ }^{\mathrm{a}}\left(\mathrm{m}^{2} \cdot \mathrm{g}^{-1}\right) \\
\text { Total } \\
\end{array}$} & \multicolumn{3}{|c|}{ Pore volume $\left(\mathrm{cm}^{3} \cdot \mathrm{g}^{-1}\right)$} \\
\hline & $\mathrm{Si}$ & $\mathrm{Al}$ & & total & micro & meso \\
\hline HY 2.5 & 260.1 & 102.1 & 1063 & 0.39 & 0.36 & 0.03 \\
\hline USY 33 & 412.5 & 12.5 & 928 & 0.47 & 0.28 & 0.19 \\
\hline MCM-41 & 380.1 & 0.0 & $984^{\mathrm{b}}$ & 0.65 & 0.00 & 0.65 \\
\hline
\end{tabular}

$9{ }^{\mathrm{a}}$ Nitrogen sorption

$10 \quad{ }^{\mathrm{b}}$ Determined using $\alpha-$ plot $^{[45]}$

$11 \quad 3.2 \quad$ Pyridine Adsorption

\subsubsection{IR Study of the Adsorption of Gas phase Pyridine over the Solids}

13 In a first step, the acid sites were studied by pyridine gas phase adsorption on the solids activated

14 in situ at $623 \mathrm{~K}$. The IR spectra of the adsorbents before pyridine adsorption are shown in Figure SI-4 and commented in the Supplementary Information. Figure 2 presents the IR spectra of the pyridine species remaining after in situ desorption at $423 \mathrm{~K}$ under secondary vacuum. The results show the presence of two interaction modes of pyridine with the acid sites. The band at $1545 \mathrm{~cm}^{-1}$ ( $\mathrm{v}_{8 \mathrm{a}}$ mode) is characteristic for pyridinium ions $\mathrm{PyH}^{+}$formed over Brønsted acid sites, while the band at $1455 \mathrm{~cm}^{-1}\left(\mathrm{v}_{19 \mathrm{~b}}\right.$ mode) reveals coordinated pyridine (LPy) over Lewis acid sites (Figure 2). ${ }^{[63,67]}$ The observed band at $1490 \mathrm{~cm}^{-1}$ is characteristic of the $v_{19 a}$ mode over both Brønsted Acid Site (BAS) and Lewis Acid Site (LAS), although its sensitivity to the concentration of BAS is higher. ${ }^{[68]}$ The concentration of both BAS and LAS can be calculated from the integration of $\mathrm{v}_{8 \mathrm{a}}$ 
1 and $\mathrm{v}_{8 \mathrm{a}}$ bands, respectively, using the following absorption coefficients: $\varepsilon_{\left(\mathrm{PyH}^{+}\right)}=1.8 \mathrm{~cm} \cdot \mu \mathrm{mol}^{-1}$

2 and $\varepsilon_{(\mathrm{LPy})}=1.5 \mathrm{~cm} \cdot \mu \mathrm{mol}^{-1} \cdot{ }^{[46]}$

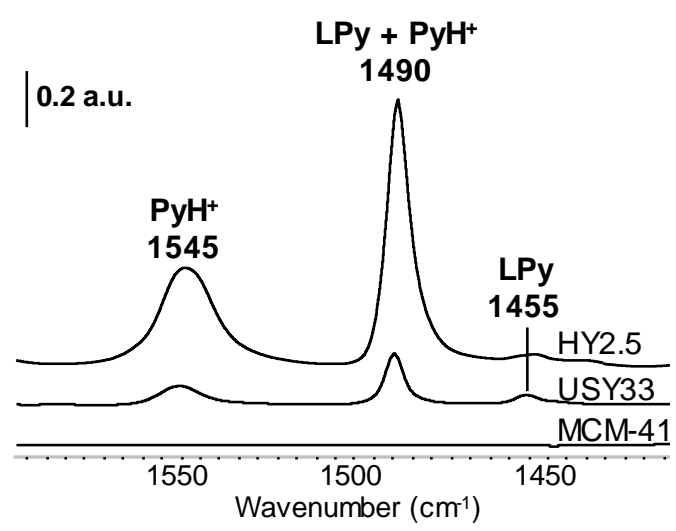

Table 2. Concentration of acidic sites in the different materials

\begin{tabular}{lccc}
\hline \multirow{2}{*}{ Adsorbents } & \multicolumn{3}{c}{ Acid sites $\left(\mu \mathrm{mol} . \mathrm{g}^{-1}\right)$} \\
\cline { 2 - 4 } & BAS & LAS & Total \\
\hline HY2.5 & 1263 & 22 & 1285 \\
USY33 & 98 & 61 & 159 \\
MCM-41 & 0 & 0 & 0 \\
\hline
\end{tabular}

Figure 2. IR spectra of the residual pyridine species over the different solids after desorption at $423 \mathrm{~K}$ under secondary vacuum.

3

Table 2 shows that the amount of BAS strongly decreases on USY33 as compared to HY2.5, whereas, the amount of LAS increases due to the formation of extraframework aluminic phase species during the dealumination treatment. ${ }^{[69,70]}$ Over MCM-41, which only presents weak-acidic silanol sites, no acid sites were evidenced after the pyridine desorption at $423 \mathrm{~K}$. These results confirm that the studied solids present various properties in terms of nature and concentration of acid sites that can serve as references to validate the characterizations developed herein.

\subsubsection{IR-ATR Study of Liquid phase Pyridine Adsorption over the Solids}

\subsubsection{IR-ATR study}

IR-ATR spectra of the thin films of Y zeolites and MCM-41 after deposition are shown in Figure 3. It must be underlined that for IR analysis in transmission and diffusion modes, of a selfsupported silica-based wafer, the structural vibration bands of the solids make the zone below $1200 \mathrm{~cm}^{-1}$ almost completely opaque. ${ }^{[69]}$ By contrast, as shown in Figure 3, these bands present limited intensities in the IR-ATR spectra of thin films, which allows their analysis. For the zeolite samples, the bands in the region at $850-650 \mathrm{~cm}^{-1}$ are characteristic of the mix of the symmetric stretching and bending modes of the T-O-T bridges ( $\mathrm{v} 2$ ). Also, these bands shift up, the lower is 
1 the $\mathrm{Al}$ content, as shown for the bands at 789 and $724 \mathrm{~cm}^{-1}$ over the HY2.5 zeolite that shift up to

2831 and $787 \mathrm{~cm}^{-1}$ over the low aluminum loaded USY33 zeolite. ${ }^{[69]}$ However, it should be noted

3 that probe molecule adsorption can induce distortion at the surface of the solids that can shift the 4 wavenumbers of these structural bands. Thus, positive - negative bands can appear on the 5 difference spectra. Hence, caution must be taken for the interpretation of the bands detected in this low wavenumber zone after the adsorption of pyridine or indole.

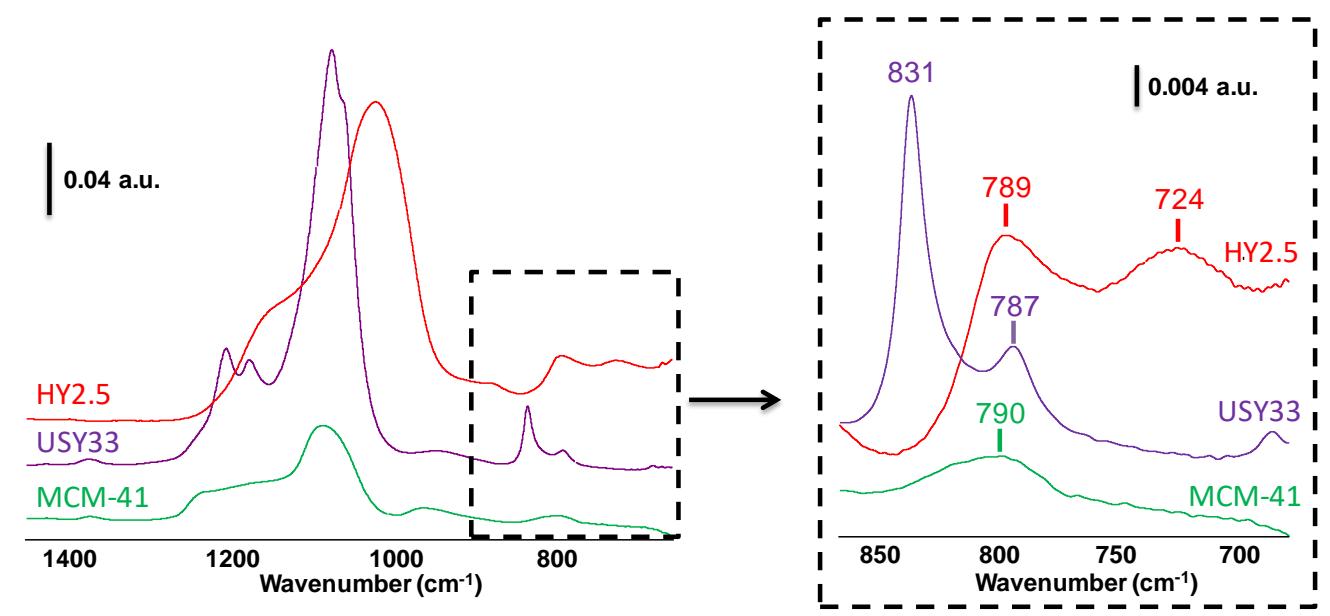

Figure 3. IR-ATR spectra of the thin films of zeolites and MCM-41 as-deposited on the ATR crystal.

8 In general, in IR-ATR mode, all the IR bands as well as those corresponding to the adsorbed

9 species present very low intensities due to the limited thickness of the samples that are analyzed

10 (a few microns). Thus, cautions must be taken in order to avoid any artifacts that can hide the

11 bands coming from adsorption. Among them, one may mention that it is important to watch the

12 stability of the concentration of water present as a contaminant in the purge of the spectrometer

13 during the experiment. Special care must be taken for spectral analysis of the region between 1400

14 and $1600 \mathrm{~cm}^{-1}$ where IR bands of water are very intense.

\subsubsection{IR-ATR study of the liquid phase pyridine - solid interaction}

IR-ATR spectra of the liquid pyridine adsorption over the films of HY2.5, USY33, and MCM-41 are presented in Figure 4. The figure compares the spectra of (1) the solution of pyridine in nhexane (dotted line), (2) the steady-state adsorption of liquid pyridine on the solid film (solid line) and (3) the strongly-adsorbed pyridine species after removing the weakly or non-adsorbed species 
1 by flushing the solid film with n-hexane (dashed line). The presented spectra are difference

2 spectra. Spectra (1) are obtained by subtraction the liquid n-hexane spectrum from the spectrum

3 of the solution of pyridine in n-hexane; spectra (2) are obtained by subtraction of the spectra of

4 pure hexane in interaction with the different solid films from the spectra corresponding to the

5 steady-state pyridine adsorption on the different solid films; spectra (3) are obtained by

6 subtraction of the spectra of pure hexane in interaction with the solid films from the spectra

7 recorded after flushing the solid films with n-hexane.

8 Over HY2.5 and USY33 zeolites (Figure 4-A and B), a large increase in the intensities of the

9 pyridine bands after adsorption is observed after comparing with the spectra recorded for the

10 liquid phase pyridine. This indicates an accumulation of pyridine molecules on the solid films and

11 confirms the adsorption phenomenon. Over the MCM-41 film, the adsorption of pyridine is

12 limited as it is indicated by the low intensity of the bands after pyridine adsorption. For the three

13 solids, the spectra show new bands when compared to those of liquid pyridine. The IR-ATR

14 spectra analyses were divided into 2 sections based on the wavenumber zones: high wavenumber zone $\left(1650-1400 \mathrm{~cm}^{-1}\right)$ and low wavenumber zone $\left(800-650 \mathrm{~cm}^{-1}\right)$.

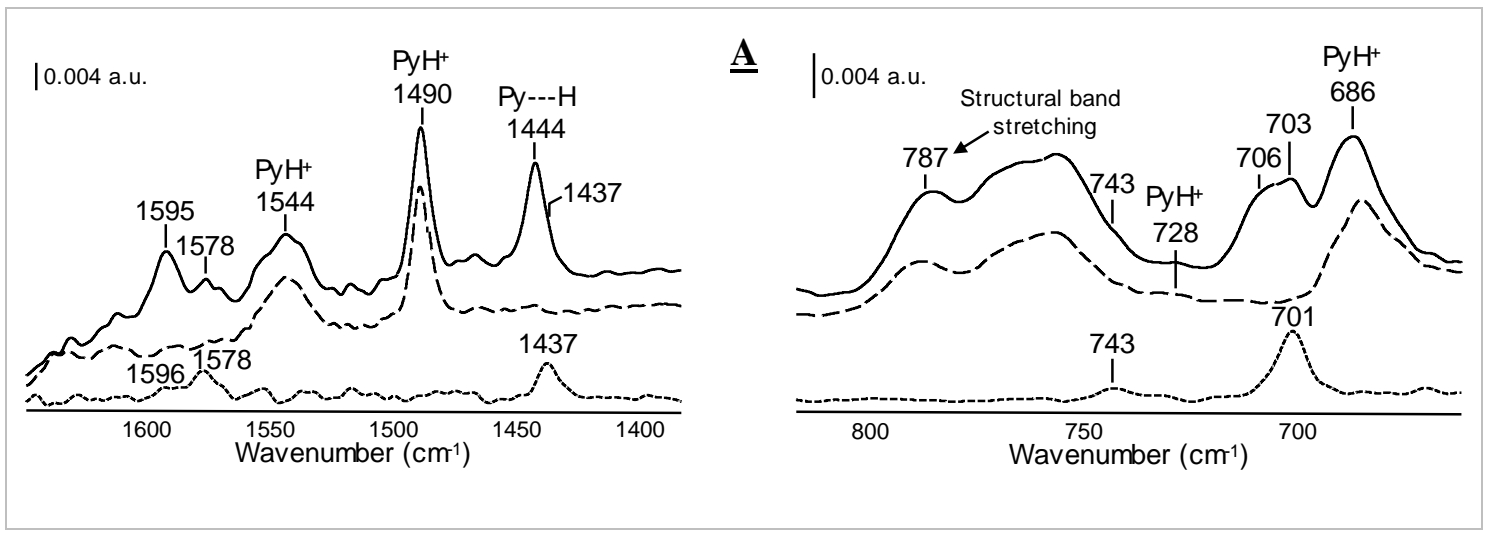




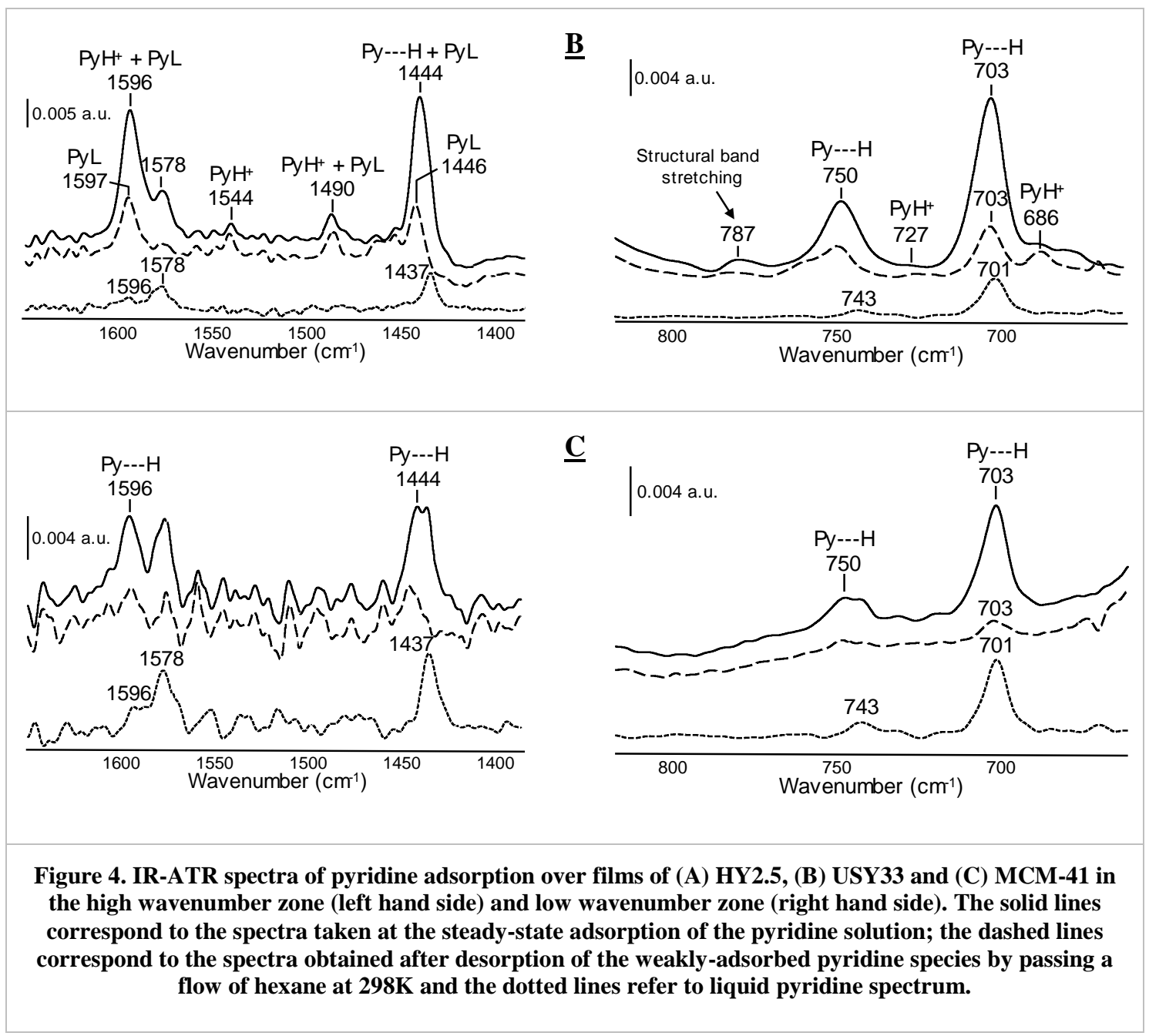

2 High wavenumber zone analysis $\left(1650-1400 \mathrm{~cm}^{-1}\right)$

3 The spectrum of adsorbed pyridine on the HY2.5 zeolite (Figure 4A - solid line) presents bands

4 at 1544 and $1490 \mathrm{~cm}^{-1}$, which characterize pyridinium ions formed over BAS. These bands remain

5 after flushing with the solvent (Figure 4A - dashed line), hence confirming that they correspond

6 to strongly adsorbed species. The bands at 1595 and $1444 \mathrm{~cm}^{-1}$ were attributed to weakly $\mathrm{H}-$

7 bonded pyridine molecules $(\mathrm{Py}---\mathrm{H})$ with the solid, ${ }^{[71,72]}$ this adsorption mode did not resist the

8 desorption under n-hexane flow. The bands for liquid pyridine were also detected during the

9 adsorption (1578 and 1437 (shoulder) $\mathrm{cm}^{-1}$ ), however, they were also eliminated during the

10 desorption.

11 Adsorption results obtained over USY33 are shown in Figure 4B. The bands related to pyridinium

12 ions (Figure 4B - solid line) are present at similar positions than over the HY2.5 zeolite (1544 and 
$11490 \mathrm{~cm}^{-1}$ ). Note that the intensity of the BAS bands is less than on HY2.5 as expected from the

2 lower Al amount of USY33 (Table 1). The bands at 1597 and $1446 \mathrm{~cm}^{-1}$ indicate the presence of

3 LAS on this partially dealuminated zeolite (Table 2). ${ }^{[63]}$ This assignment is confirmed by the

4 stability of these species under flowing hexane. In addition, the bands of pyridine interacting with

5 silanol groups (1596 and $\left.1444 \mathrm{~cm}^{-1}\right)$ and liquid phase pyridine $\left(1578\right.$ and $\left.1437 \mathrm{~cm}^{-1}\right)$ were also

6 detected. However, these bands disappeared by flushing with n-hexane (Figure 4B - dashed line).

7 Over the MCM-41 film, pyridine bands are not intense (Figure 4C - solid line), even being hard

8 to tell them apart from the spectral noise. The spectra mainly exhibit the bands for liquid pyridine.

9 Only two bands at 1596 and $1444 \mathrm{~cm}^{-1}$ indicate the formation of weakly-adsorbed H-bonded pyridine species. Rivera et al. reported a similar pattern for pyridine adsorption in the liquid phase on silica, ${ }^{[27]}$ which allowed observing mainly the characteristic bands of liquid pyridine. They reported the appearance of one weak band at $1492 \mathrm{~cm}^{-1}$ attributed to pyridinium ions, indicating the presence of strong acid sites. This suggests some Al contamination in the silica. These authors also highlighted the presence of noise in the spectra ascribed to water in the vapor phase that distorts the spectra between 1600 and $1400 \mathrm{~cm}^{-1}$, which makes difficult to distinguish pyridine bands in this region.

The acidic site nature of the solids detected by pyridine under liquid phase is in good agreement with that obtained with pyridine under gas phase (section 3.2.1 - Table 2). It is not possible to make a quantitative assessment of the acidic sites by IR-ATR due to the absence of accurate knowledge of the volume of solids probed by the ATR signal. However, a comparison of the ratio between the various pyridine species formed over the tested solids in the gas and liquid phases experiments can be done. The ratios of the areas of the bands located at $1490 \mathrm{~cm}^{-1}(\mathrm{H}$-bonded and coordinated pyridine) and $1544 \mathrm{~cm}^{-1}$ (protonated pyridine) were compared for pyridine adsorption performed in the gas-solid conditions in the IR transmission set up (areas measured after pyridine evacuation at 423K) (Figure 2) and performed in the liquid-solid with IR-ATR set up (areas measured under hexane flow) (Figure 4). Note that the widespread of the noise across the IR-ATR spectra limits an accurate measurement of the band area. The ratios reach values of 1.3 (gas 
1 experiment) and 1.5 (liquid experiment) over USY33. Over HY2.5 zeolite, the ratios for gas and

2 liquid experiments were, even more, close with a value of almost 1.1 in both experiments. A good

3 agreement between gas and liquid phase adsorption of pyridine is thus shown.

4

5

6

\section{Low wavenumber zone analysis $\left(800-650 \mathrm{~cm}^{-1}\right)$}

The study of the zone from 650 to $800 \mathrm{~cm}^{-1}$ presents the great advantage to overcome the problem of the spectral noise induced by the water present in the vapor purge. Indeed, water vapor does not present any vibration-rotation bands in this zone and IR-ATR allows the analysis of this spectral zone for thin films of zeolites and oxides. However, as mentioned previously, some solid structural bands are detected in the region of low-frequency $\left(800-650 \mathrm{~cm}^{-1}\right)$ (Figure 3) and these bands can be shifted by structural distortion due to pyridine adsorption on the solid. This warns that caution should be taken for the interpretation of the bands in this zone. As for the HY2.5 zeolite, an assignment of bands characteristic of weakly adsorbed species or non-adsorbed ones can be proposed by comparing pyridine spectra obtained before and after flowing hexane regarding the spectrum of liquid pyridine (Figure $4 \mathrm{~A}$ - right). Hence, the band at $706 \mathrm{~cm}^{-1}$ can be attributed to $\mathrm{H}$-bonded pyridine, while the bands at 743 and $703 \mathrm{~cm}^{-1}$ are related to pyridine in the liquid phase. The strong band at $686 \mathrm{~cm}^{-1}$ that resists to hexane flushing likely accounts for pyridinium species. However, due to the presence of strong (str) structural bands between 800$740 \mathrm{~cm}^{-1}$ on HY2.5 (Figure 3), the bands detected at 787 (str), 760 (str), 728 (w-weak) $\mathrm{cm}^{-1}$ after pyridine adsorption can arise from a shift of the structural band or pyridine species. Their assignment being shaky with only experimental data, pyridine adsorption frequencies were computed by DFT calculation to validate the proposed assignments (see next section).

On USY33 zeolite, the structural bands present limited intensity in the region below $780 \mathrm{~cm}^{-1}$ (Figure 3), allowing an easier assignment of the pyridine adsorption bands on this solid. During the adsorption of pyridine, new bands appear at 750(str), 727(w), 703(str), 686(m-medium) $\mathrm{cm}^{-1}$ (Figure 4B and its zoom in Figure 5). The intense bands at 750 and $703 \mathrm{~cm}^{-1}$, that are partially eliminated by flushing, can be assigned to pyridine adsorbed over silanol groups. This is in good agreement with the assignment proposed in the previous section. The bands detected at 727 and 
1 at $686 \mathrm{~cm}^{-1}$ whose stability under flushing is clearly observed in Figure 5, should characterize

2 protonated pyridine as proposed on HY2.5 zeolite. A more robust assignment will be done after

3 comparison with the frequencies calculated by DFT (section 3.2.3).

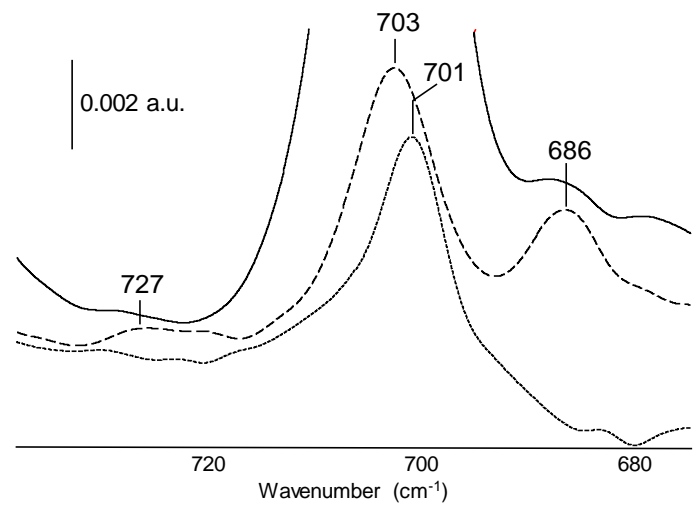

Figure 5. IR-ATR spectra of pyridine adsorbed on USY33 and comparison with pure pyridine (zoom of the Figure 4B right). The solid line corresponds to the steady-state adsorption of the pyridine solution; the dashed line corresponds to the spectrum obtained after desorption of the weakly adsorbed species by passing a flow of hexane at $298 \mathrm{~K}$ and the dotted line refers to liquid pyridine spectrum.

In summary, a good agreement was observed between pyridine adsorption in gas and liquid phases. However, IR-ATR spectra present low intense bands, and the analysis of the region between 1600 and $1400 \mathrm{~cm}^{-1}$ was difficult due to the presence of water bands as a contaminant in the spectrometer gas purge. ${ }^{[27,30]}$ Nevertheless, an advantage of the IR-ATR setup is in giving access to analyze the low wavenumber zone $\left(800-650 \mathrm{~cm}^{-1}\right)$, where no water bands appear. Pyridine exhibits some intense bands in this zone that provide interesting information about the adsorption mode of pyridine in the liquid-solid IR-ATR analysis. ${ }^{[73]}$ To go further, DFT calculations were performed in order to predict expected frequencies according to the interaction mode of pyridine with the surface.

\subsubsection{Theoretical Assessment of the Adsorption of Pyridine}

Most of the IR studies using pyridine for probing the acid sites focus on the region between 1400 and $1700 \mathrm{~cm}^{-1}$. The corresponding in-plane atomic displacements for the pyridine vibrational modes appearing in this wavenumber zone $\left(v_{8 \mathrm{a}}, v_{8 \mathrm{~b}}, v_{19 \mathrm{a}}\right.$ and $\left.v_{19 \mathrm{~b}}\right)$ are shown in Figure $6 .{ }^{[74]}$ Our work points out the interest of accurately analyzing the vibrational zone between 800 and $600 \mathrm{~cm}^{-}$ 
$1 \quad{ }^{1}$ for helping in understanding the interaction between liquid pyridine and the solid films. Within

2 the low-frequency zone, $v_{10 \mathrm{~b}}$ and $v_{11}$ modes are two characteristic signals of pyridine that 3 correspond to out-of-plane motions (Figure 6).
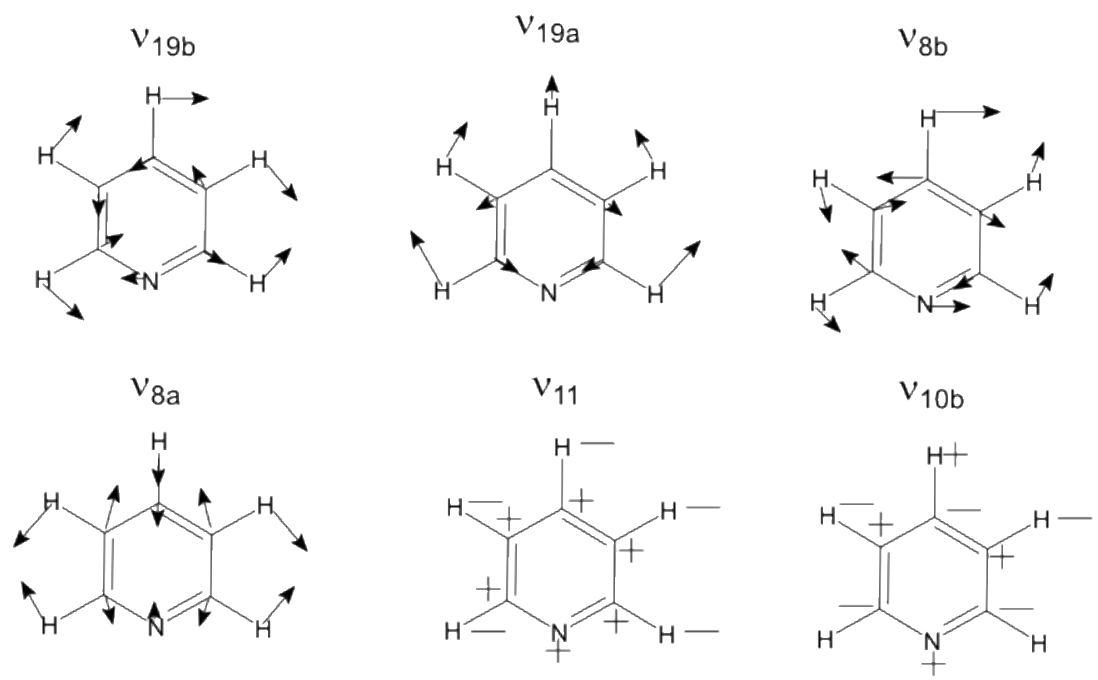

Figure 6. Atomic displacements for the commonly studied vibrational modes of pyridine.

4 Table 3 gathers the frequencies in the high-wavenumber and low-wavenumber zones calculated

5 by DFT for the various vibration modes of gas-phase pyridine, H-bonded, and protonated pyridine. The frequencies of coordinated pyridine molecules over a Lewis acid site were not computed in this work. Table 3 also compares the theoretical and experimental frequencies obtained in this work to theoretical frequencies found in the literature. ${ }^{[42]}$ In general, a good agreement appears between the frequencies calculated for pyridine in the gas phase and those for pyridine adsorbed over the various sites. The calculations show that $\mathrm{H}$-bonding leads to limited changes in wavenumbers compared to pure pyridine. This agrees with the fact that the interaction of pyridine with a silanol can be described as physical adsorption.

In the high-wavenumber zone, the vibrational frequencies predicted for pyridine on silanol groups

14 are in good agreement with the values obtained experimentally (Table 3). For this kind of 15 interaction, the characteristic vibrations of the pyridine molecules are very similar to those observed for pyridine in the gas phase. Only when the interaction is strong enough, a chemisorbed complex of pyridine on a Brønsted site, some changes are observed in the motions of the pyridine 
1 molecules. ${ }^{[42,75]}$ These changes could explain the registered shifts which are characteristic of the

2 ion-pair H-bonded complexes described in the literature. ${ }^{[2,76]}$

3 For the interaction of pyridine with the Brønsted acid sites, the predicted shifts of the vibrational

4 modes $v_{8 \mathrm{a}}$ and $v_{19 \mathrm{a}}$ were similar to what was previously reported in the literature. ${ }^{[42]}$ However, for

5 the $v_{8 \mathrm{~b}}$ and $v_{19 \mathrm{~b}}$, vibration modes, the previously calculated values were slightly higher as

6 compared to the experimental data. ${ }^{[42]}$ The computed values obtained herein are more realistic

7 (Table 3). Previous calculations considered a $12 \mathrm{~T}_{\mathrm{OH}}$ size cluster ${ }^{[42]}$ while in the present work the

8 adsorption occurs on a Brønsted acid site located in the pore mouth of a 193-atom mordenite.

Table 3. Comparison between the predicted vibrational frequencies and the experimental values obtained in

IR-ATR for pyridine adsorption over silanol groups and Brønsted acid sites.

\begin{tabular}{|c|c|c|c|c|c|c|c|c|}
\hline \multirow{3}{*}{$\begin{array}{l}\text { Vibrational } \\
\text { mode* }\end{array}$} & \multicolumn{8}{|c|}{ Pyridine frequencies $\left(\mathrm{cm}^{-1}\right)$} \\
\hline & \multicolumn{2}{|c|}{ Gas phase } & \multicolumn{3}{|c|}{ Silanol group } & \multicolumn{3}{|c|}{ Brønsted site } \\
\hline & 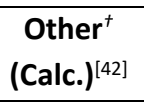 & $\begin{array}{l}\text { This work } \\
\text { (Calc.) }\end{array}$ & 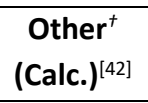 & $\begin{array}{l}\text { This work } \\
\text { (Calc.) }\end{array}$ & $\begin{array}{l}\text { This work } \\
\text { (IR-ATR) }\end{array}$ & 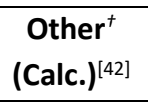 & $\begin{array}{l}\text { This work } \\
\text { (Calc.) }\end{array}$ & $\begin{array}{l}\text { This work } \\
\text { (IR-ATR) }\end{array}$ \\
\hline $8 a$ & 1595 & 1587 & 1612 & 1595 & 1597 & 1634 & 1634 & - \\
\hline $8 b$ & 1591 & 1574 & 1591 & 1573 & 1578 & 1669 & 1621 & - \\
\hline $19 b$ & 1445 & 1432 & 1464 & 1437 & 1444 & 1563 & 1547 & 1544 \\
\hline $19 a$ & 1486 & 1472 & 1487 & 1475 & 1485 & 1486 & 1485 & 1490 \\
\hline 11 & - & 742 & - & 745 & 750 & - & 721 & 728 \\
\hline $10 b$ & - & 699 & - & 706 & 703 & - & 686 & 686 \\
\hline
\end{tabular}

11 *Wilson's numbers for the vibrational modes of the benzene ring. ${ }^{*}$ Theoretical data from other work, 12 calculated for the pyridine interaction on a Brønsted acid site in a $12 \mathrm{~T}_{\mathrm{OH}}$ zeolite cluster using the $B 3 L Y P / 6$ -

$1331 G(d, p)$, as reported in reference. ${ }^{[42]}$

14 This work presents, as far as we know, the first calculation of the vibrational frequencies of 15 pyridine in the region of low-frequency $\left(800-650 \mathrm{~cm}^{-1}\right)$. Two intense bands were observed: $v_{10 b}$ 16 and $v_{11}$, which correspond to out-of-plane vibrations (Figure 6). For the $v_{10 \mathrm{~b}}$ and $v_{11}$ modes over 17 a silanol, a small shift was found with bands predicted at 745 and $706 \mathrm{~cm}^{-1}$. This agrees with the observation done for liquid pyridine adsorption over the MCM-41 film (H-bonded bands at 750 and $703 \mathrm{~cm}^{-1}$ ). Meanwhile, for the interactions with a Brønsted site, characteristic bands at 728 and $680 \mathrm{~cm}^{-1}$ of pyridinium species are predicted. ${ }^{[73]}$ Hence, based on the calculated frequencies

21 of pyridine chemisorbed on Brønsted sites, the bands observed at 727 and $686 \mathrm{~cm}^{-1}$ during the IR- 
1 ATR analysis of liquid pyridine - zeolite interaction (Figure 4) can be assigned to pyridinium

2 species.

3 In summary, a good agreement is observed between the predicted (by DFT calculation) and experimental (using the liquid phase IR-ATR study) vibrational frequencies of the pyridine adsorption over silanol groups and Brønsted acid sites. In the high wavenumber zone (1650 -

$61400 \mathrm{~cm}^{-1}$ ), as expected, the bands observed at 1544 and $1490 \mathrm{~cm}^{-1}$ were assigned to protonated

7 pyridine molecules over the Brønsted sites of the zeolites. Most notably, in the low frequency zone $\left(850-600 \mathrm{~cm}^{-1}\right)$ the experiments and DFT calculations allows establishing that the bands observed at 750 and $703 \mathrm{~cm}^{-1}$ correspond to $\mathrm{H}$-bonded pyridine species whereas the bands at 727 and $686 \mathrm{~cm}^{-1}$ can be assigned to pyridinium ions formed over the Brønsted acid sites of the zeolites.

In the next section, the study of the adsorption and protonation of indole will be investigated over the previously studied adsorbents. To go further, DFT calculations were performed in order to predict expected frequencies according to the mode of interaction of indole with the surface.

\subsection{Indole Adsorption}

\subsubsection{IR-ATR Study of Liquid phase Indole Adsorption over the Solids}

Spectra corresponding to dissolved indole and indole adsorbed over HY2.5, USY33, and MCM-

41 in the high and low-wavenumber zones are presented in Figure 7. The IR-ATR spectrum of liquid indole (dotted line) shows bands at $1455,1414 \mathrm{~cm}^{-1}$ and a shoulder at $1468 \mathrm{~cm}^{-1}$ in the high wavenumber zone as well as bands at $768,763,738$ and $716 \mathrm{~cm}^{-1}$ in the low wavenumber zone. The solution flowed over the ATR crystal contained indole diluted into hexane (0.5 wt.\%). To obtain the indole spectrum, the bands of hexane must be eliminated by subtracting the spectra of pure $n$-hexane. Since n-hexane presents intense bands at 1468 and $728 \mathrm{~cm}^{-1}$, the shoulders observed in the indole spectrum at these wavenumbers should correspond to partially eliminated n-hexane bands after the subtraction. Thus, these two bands will not be considered in the assignment of the indole bands. 
1 After indole adsorption over the HY2.5 zeolite film (Figure 7A), bands appear at 1617, 1608,

21543,1489 , and $1455 \mathrm{~cm}^{-1}$, in the high-wavenumber zone. In the low-wavenumber zone, bands

3 are detected at $\sim 758,738,716$ and $702 \mathrm{~cm}^{-1}$. However, a broad massif also appears at 787-750

$4 \mathrm{~cm}^{-1}$. As previously noticed for pyridine adsorption on HY2.5 (Figure 4), this massif was

5 attributed to the change in the frequency of the vibrations of the T-O-T bridges during the indole

6 adsorption. During desorption under n-hexane flow, most of these bands resist flushing and

7 remain present with lower intensities (dashed line).

8 The indole adsorption over the USY33 zeolite film (Figure 7B) shows new bands at 1543, 1514,

91489,1455 , and $1414 \mathrm{~cm}^{-1}$ in the high-wavenumber zone and $767,743,718$, and $702 \mathrm{~cm}^{-1}$ in the

10 low-wavenumber zone. Most of these bands were observed on HY2.5 spectra even if with

11 different intensities. As previously shown over HY2.5, during the desorption most of these bands lose intensity but withstand rinsing under the solvent flow. Only the band at $1414 \mathrm{~cm}^{-1}$ disappears totally which allows to attribute it to weakly-adsorbed indole species (Figure 7B and Figure 8).

14 The zoom presented Figure 8 makes clearly visible that the bands at 728, 718 and $706 \mathrm{~cm}^{-1}$ resist to the n-hexane flush.

Over the MCM-41 film (Figure 7-C), bands at 1455, 1414 as well as 768, 763, 745, 738, and 716 $\mathrm{cm}^{-1}$ are observed. These bands are very close to those of liquid indole. Moreover, they completely disappear after flowing hexane, which confirms that indole species are not strongly adsorbed over

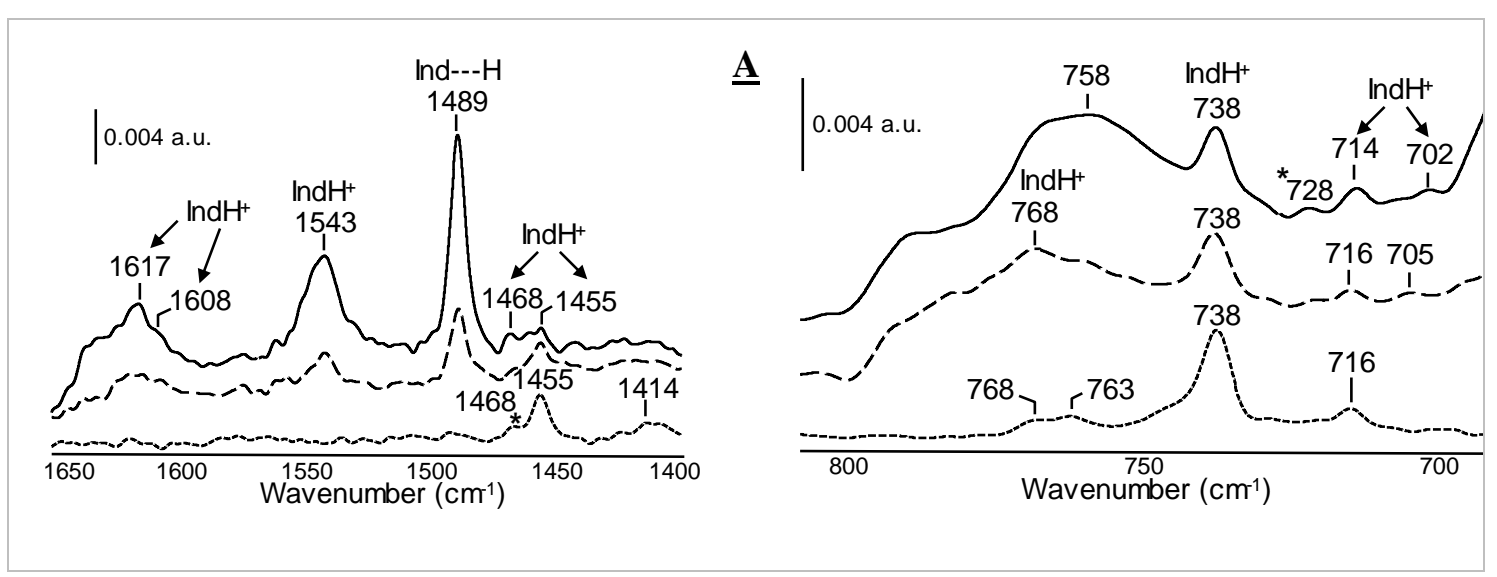




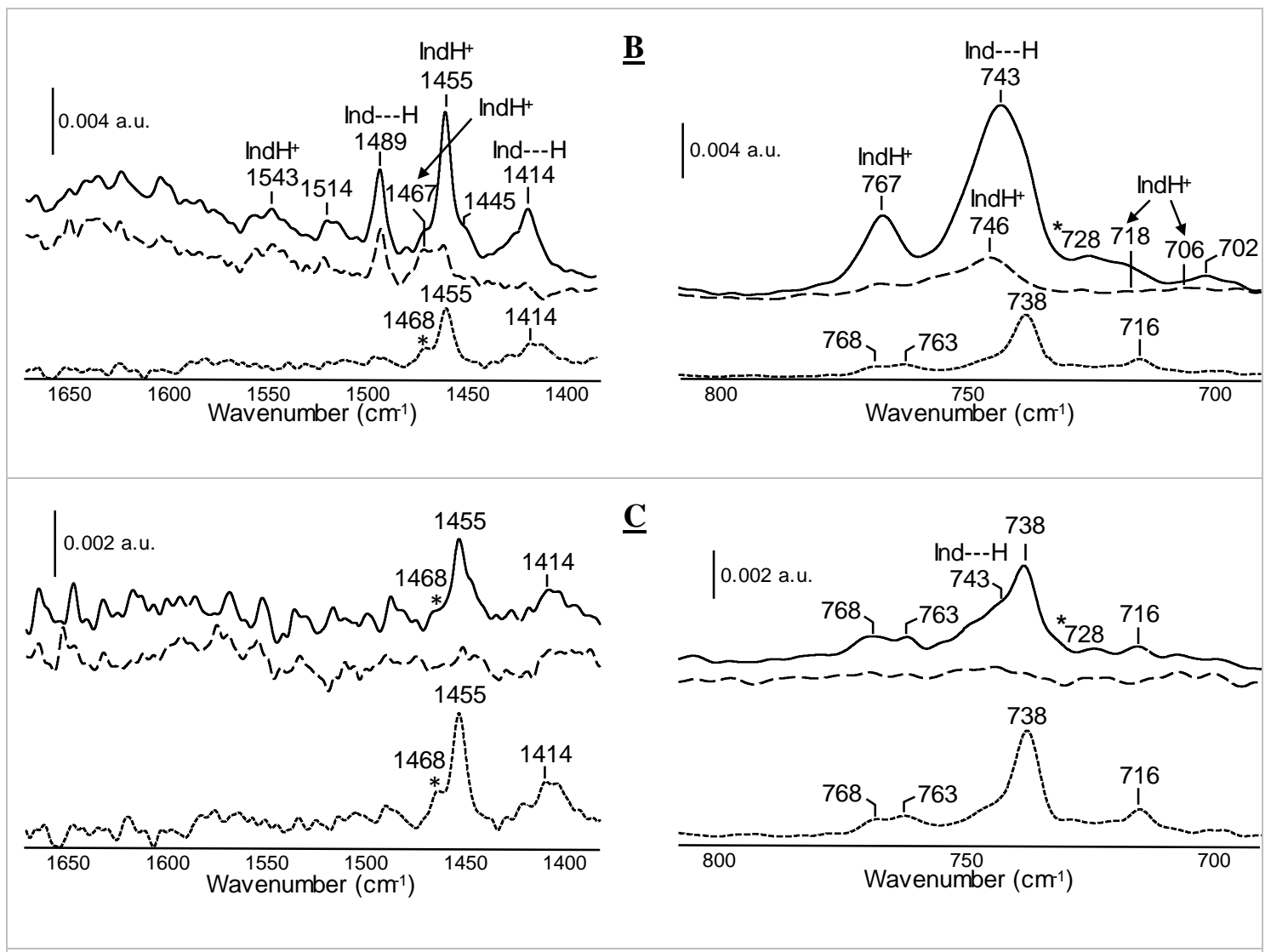

Figure 7. IR-ATR difference spectra of the indole adsorption over (A) HY2.5, (B) USY733 and (C) MCM-41 film in the region of high-wavenumber (left hand side) and low-wavenumber (right hand side). The solid lines correspond to the spectra of steady-state adsorption of the indole solution; the dashed lines correspond to the spectra obtained after desorption of the weakly adsorbed species by passing through the solvent at 298K and the dotted lines refer to indole spectra in $\mathrm{n}$-hexane. [* this component can correspond to a characteristic band for $n$-hexane]

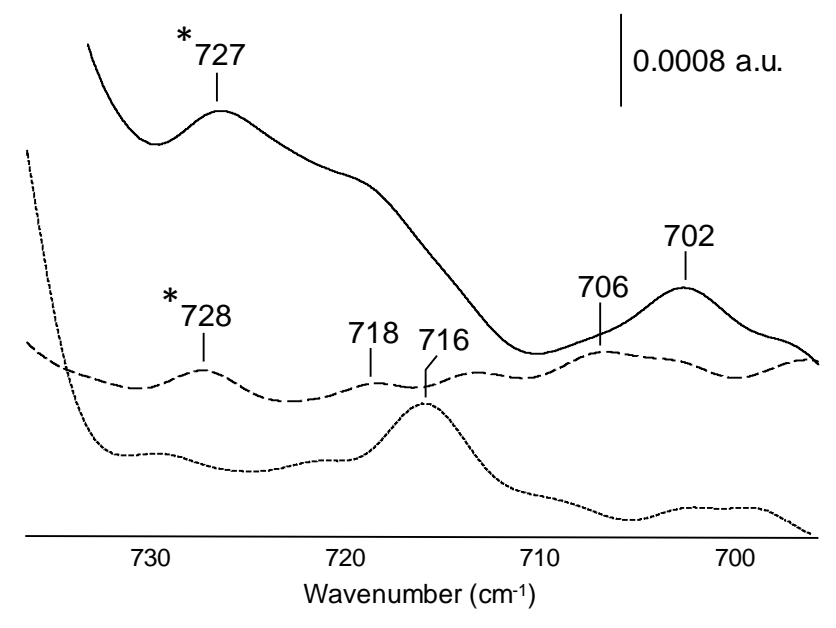

Figure 8. IR-ATR spectra of the indole adsorption over USY33 zeolite and of pure indole (Zoom of the Figure 7B - right). The solid line corresponds to the spectrum of the steady-state adsorption of the indole solution; the dashed line corresponds to the spectrum obtained after desorption of the weakly adsorbed species by passing through the solvent at $298 \mathrm{~K}$ and the dotted line refers to indole spectrum in $\mathrm{n}$-hexane. [* this component can correspond to a characteristic band for n-hexane] 


\section{$1 \quad$ 3.3.2 Theoretical Assessment of the Adsorption of Indole}

2 To assign the bands recorded on the IR-ATR spectra, DFT calculations of the vibrational

3 frequencies of indole either in the gas phase or adsorbed on silanol or Brønsted acid sites were

4 performed in the high and low-wavenumber zones. Indole can interact with the silanol group and

5 with the zeolitic $\mathrm{OH}$ groups as depicted in Figure 9. The H-bonded interaction involves an

6 interaction between the $\mathrm{NH}$ group of the indole molecule and the oxygen atom from the zeolite

7 framework, as well as an interaction between the $\mathrm{SiOH}$ group and $\alpha$-carbon of the $\mathrm{C} 5$ cycle. In

8 such a configuration, the distance between the $\mathrm{H}$ of the $\mathrm{SiOH}$ group and the $\alpha$-carbon is about

$9 \quad 1.95 \AA$. The most stable configuration of protonated indole was obtained over the carbon in

10 position 3 (C3 site). A similar configuration was obtained by Somers et al. ${ }^{[62]}$

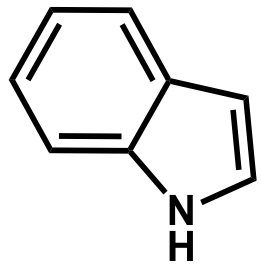

Gas phase

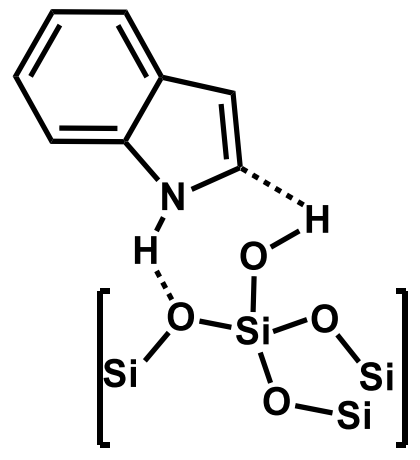

Terminal silanol group

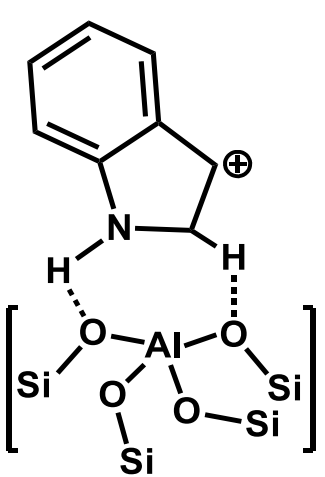

Brønsted acid site

Figure 9. The three evaluated configurations for the calculation of the vibrational frequencies for indole adsorption.

11 The predicted vibrational frequencies for indole in the gas phase, interacting with the silanol group

12 or with a protonated $\mathrm{OH}$ group of the zeolite were calculated and are reported in Table 4.

\begin{tabular}{|c|c|c|c|c|c|c|c|}
\hline \multirow{3}{*}{$\begin{array}{l}\text { Vibrational } \\
\text { modes }\end{array}$} & \multicolumn{7}{|c|}{ Indole frequencies $\left(\mathrm{cm}^{-1}\right)$} \\
\hline & \multicolumn{2}{|c|}{ Gas phase } & \multirow{2}{*}{$\begin{array}{c}\text { Liquid phase } \\
\text { This work } \\
\text { (IR-ATR) }\end{array}$} & \multicolumn{2}{|c|}{ Silanol group } & \multicolumn{2}{|c|}{ Brønsted acid site ${ }^{b}$} \\
\hline & {$[\text { Ref }]^{\mathrm{a}}$} & $\begin{array}{c}\text { This } \\
\text { work } \\
\text { (Calc.) }\end{array}$ & & $\begin{array}{l}\text { This work } \\
\text { (Calc.) }\end{array}$ & $\begin{array}{l}\text { This work } \\
\text { (IR-ATR) }\end{array}$ & $\begin{array}{l}\text { This work } \\
\text { (Calc.) }\end{array}$ & $\begin{array}{c}\text { This work } \\
\text { (IR-ATR) }\end{array}$ \\
\hline & 1614 & 1613 & - & 1615 & 1617 & 1623,1600 & 1617,1608 \\
\hline
\end{tabular}




\begin{tabular}{|c|c|c|c|c|c|c|c|}
\hline & 1576 & 1575 & - & 1573 & - & - & - \\
\hline In-Plane & - & - & - & - & - & 1554 & 1543 \\
\hline \multirow{4}{*}{$\begin{array}{l}\text { Quadrant and } \\
\text { Semicircular } \\
\text { Stretching of } \\
\text { the rings }\end{array}$} & 1505 & 1505 & - & 1496 & 1489 & - & - \\
\hline & 1486 & 1485 & - & 1482 & 1489 & 1468 & 1468 \\
\hline & 1456 & 1444 & 1455 & 1442 & 1445 & 1450 & 1455 \\
\hline & 1415 & 1416 & 1415 & 1411 & 1414 & - & - \\
\hline \multirow{5}{*}{$\begin{array}{l}\text { Out-of-plane } \\
\text { vibrations of } \\
\text { the rings and } \\
\mathrm{H} \text { atoms }\end{array}$} & 765 & 757 & 768 & 774 & 767 & 768 & 768 \\
\hline & 747 & 755 & 763 & 758 & - & 740 & $738 / 746$ \\
\hline & 731 & 731 & 738 & 745 & 743 & 717 & 716 \\
\hline & 719 & 709 & 716 & 737 & - & - & - \\
\hline & - & - & - & - & - & 700 & 705 \\
\hline
\end{tabular}

1 aMNIC database, Aldrich Catalog No: I-340-8

$2{ }^{\mathrm{b}} \mathrm{C} 3$ protonated indole

3 For indole in the gas phase, the calculations predicted several bands in the region of high

4 frequencies; namely, 1613, 1575, 1505, 1485, 1444, and $1416 \mathrm{~cm}^{-1}$. These bands are attributed to

5 in-plane vibrational modes of the 6 and 5-membered rings (Figure 10). In the region from 800 to

$6 \quad 650 \mathrm{~cm}^{-1}$, calculated vibrational modes corresponding to out-of-plane motions are predicted at

$7 \quad 757,755,731$, and $709 \mathrm{~cm}^{-1}$. 

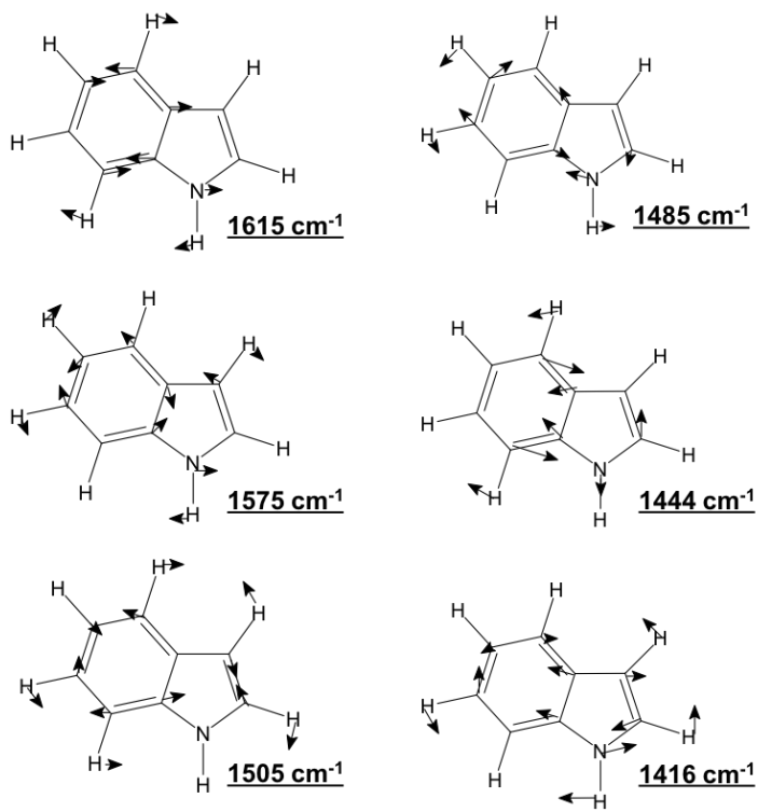

Figure 10. Atomic displacements for in-plane vibrational modes of indole in the gas phase in the region of 1400 to $1600 \mathrm{~cm}^{-1}$.

1 Indole keeps the same atomic motions as in the gas phase and small shifts are predicted compared

2 to gas-phase frequencies when the molecule is $\mathrm{H}-$ bonded to silanol groups. Table 4 shows that $\mathrm{H}-$

3 bonded indole should give rise to bands at 1615,1573,1496,1482,1442, and $1411 \mathrm{~cm}^{-1}$ in the

4 high-wavenumber zone. Concerning the low-wavenumber zone, bands at 774, 758, 745, and 737

$5 \mathrm{~cm}^{-1}$ should be observed. On the contrary, for indole interacting with a Brønsted acid site, the

6 calculations predicted shifts in the $\mathrm{C}-\mathrm{C}$ stretching modes of the $\mathrm{C} 5$ and $\mathrm{C} 6$ cycles. This could be

7 attributed to the change in the vibrational modes of the adsorbed molecule, even some additional

8 modes can be predicted over the protonated atom (C3). Hence, the supplementary band at 1554

$9 \mathrm{~cm}^{-1}$ corresponds to a $\mathrm{C}-\mathrm{C}$ stretching vibration of the protonated carbon $\left(\mathrm{sp}^{3}\right)$ of the indole rings

10 (Table 4). In the region of low-frequency, the theoretical calculation of indole on a Brønsted acid

11 site has shown a new band at $700 \mathrm{~cm}^{-1}$ attributed to out-of-plane motions of the hydrogen atoms

12 of the C5 cycle.

13 The vibrational frequencies predicted for gas-phase indole adsorbed on a silanol terminal group and a Brønsted site of a mordenite can be summarized as follows: (i) for the interactions of indole with silanol groups small shifts were obtained; (ii) for protonation of indole more important shifts

16 are expected and new bands should appear. Next, the calculated vibration frequencies were 
1 compared to the experimental spectra in order to assign the observed bands and identify the indole

2 adsorption modes on the different solids.

\section{Comparison between calculated and observed vibrational frequencies of indole}

4 The reference gas phase spectrum of indole (Figure SI-5, spectra from the Omnic database and

5 Table 4) presents bands at very similar wavenumbers to the computed ones. On the experimentally

6 IR-ATR spectrum of indole in the liquid phase (Figure 7), the most intense bands are observed at

$71455 \mathrm{~cm}^{-1}$ and $1414 \mathrm{~cm}^{-1}$, while those at $1613,1575,1505$, and $1485 \mathrm{~cm}^{-1}$ were not detected (Table

8 4). This is likely due to the low amount of indole in the n-hexane mixture $(0.5 \mathrm{wt} . \%)$ and the low

9 intensity of IR-ATR spectra.

10 A parallel between the computed vibrational frequencies (Table 4) and the recorded spectra of indole on HY2.5 (Figure 7A) allows assigning the bands at 1617, 1608, and $1543 \mathrm{~cm}^{-1}$ to protonated indole species. These protonated species were also detected on USY33 (Figure 7B), however, the bands were less intense which agrees with the lower concentration of BAS over the dealuminated USY zeolite (Table 2). The noisy spectra and the lower concentration of protonated indole prevent the detection of the bands at 1617 and $1608 \mathrm{~cm}^{-1}$ on USY33. As expected, the characteristic bands for protonated indole species were not detected on MCM-41. The band at $1489 \mathrm{~cm}^{-1}$ detected on both HY2.5 and USY33 zeolites can be assigned straightforwardly to Hbonded indole (Table 4), while the assignment of the bands at 1455 and $1468 \mathrm{~cm}^{-1}$ was not as obvious. Table 4 shows that the band at $1455 \mathrm{~cm}^{-1}$ can be characteristic for both protonated indole and liquid phase indole, whereas the band at $1468 \mathrm{~cm}^{-1}$ can be assigned to protonated indole or, alternatively, to the presence of residual n-hexane in the difference spectrum, thus making difficult to assign these bands to a unique species.

In the low wavenumber zone, liquid indole presents four bands at $768,763,736,716 \mathrm{~cm}^{-1}$, which matches satisfactorily with the calculated frequencies (Table 4). The main question to answer when analyzing the low-wavenumber region is: does this spectral region confirm the formation of protonated indole species on faujasites samples? Table 4 shows that a characteristic band of protonated indole species should appear at about $700 \mathrm{~cm}^{-1}$. First, it must be underlined that the 
1 experimental spectrum of liquid indole or indole on MCM-41 does not present any band at about

$2700 \mathrm{~cm}^{-1}$ (Figure 7C). On HY2.5, and similarly on USY33, Figure 7A and Figure 7B (and more

3 clearly the zoom presented in Figure 8) point out a weak band at $702 \mathrm{~cm}^{-1}$ which shifts to $705 \mathrm{~cm}^{-}$

$4{ }^{1}\left(706 \mathrm{~cm}^{-1}\right.$ for USY33) after flowing with the solvent. Thus, both high and low- wavenumber

5 zones provide spectroscopic evidence for indole protonation through the appearance of bands at

$6 \quad 1543 \mathrm{~cm}^{-1}$ (as well as $1617,1608 \mathrm{~cm}^{-1}$ ) and $705 \mathrm{~cm}^{-1}$. The other features detected at 767, 746-738,

7 and $716 \mathrm{~cm}^{-1}$ both on HY2.5 and USY33 can support indole protonation but can be also assigned

8 to H-bonded indole.

9 Over the MCM-41 film (Figure 7-C), only the liquid indole bands were detected in the high wavenumber zone. In the low-wavenumber zone, a small shoulder was observed at $745 \mathrm{~cm}^{-1}$ attributed to weakly adsorbed indole molecules over a silanol group. All bands disappear after flowing with n-hexane, which confirms the weak interaction of indole with the siliceous film.

13 Considering the collected evidence, this IR-ATR study reveals that indole, a weakly basic compound, can be protonated on acidic Y zeolites as unambiguously evidenced by the formation of the bands at $1617,1608,1543$, and $705 \mathrm{~cm}^{-1}$. In this way, Laredo et al. attempted to separate basic from weakly basic nitrogenates in a heavy oil fraction by using solid acids. ${ }^{[77]}$ The separation was not efficient, and this was ascribed to the strong adsorption of the weakly basic compounds on the employed materials. Therefore, the interaction of indole with Brønsted acid sites via the formation of an ion-pair complex is feasible, contrary to the suggested mechanism of dissociative adsorption. ${ }^{[78]}$ Such interactions should also alter the surface chemistry of these materials and thus block the Brønsted acid sites. These findings draw attention to the possible role of weakly basic nitrogen compounds that can modify the catalytic performance of zeolitic materials employed for hydrocracking units. ${ }^{[4]}$

\section{CONCLUSIONS}

The interaction modes of liquid phase pyridine and indole over HY and USY zeolites and MCM41 solid films were successfully studied by using an in situ liquid-solid IR-ATR setup and 
1 theoretical calculations. Using IR-ATR system offers two main advantages, it allows : (1) the

2 analysis of the low frequency region $\left(<800 \mathrm{~cm}^{-1}\right)$ that presents characteristic vibrational modes

3 of adsorbed species, (2) studying the adsorption of low vapor pressure molecules (such as indole)

4 that presents an inherent difficulty to be operated in the gas phase IR cells.

5 A parallel between the vibrational frequencies predicted by DFT calculations, and the 6 experimental results obtained using the IR-ATR cell for studying of the solid films under 7 continuous liquid flow shows that:

- As for pyridine, the low wavenumber zone, a newly explored zone, can also account for its adsorption modes. Indeed, the IR bands at 686 and $727 \mathrm{~cm}^{-1}$ characterize the pyridinium species formed on zeolitic $\mathrm{OH}$ groups, while the signals at 703 and $750 \mathrm{~cm}^{-1}$ are associated with pyridine in interaction with silanol groups.

- As for indole, the IR-ATR study points out the presence of new bands after its adsorption over Y zeolites and MCM-41. Over the zeolites, the detection of bands at 1617, 1608, 1543 and $705 \mathrm{~cm}^{-1}$ provides evidence for the formation of protonated indole species over acidic $\mathrm{OH}$ groups.

These findings support the fact that indole, a weakly basic nitrogenates, can be protonated over the zeolitic acid sites and thus decreasing their activity during the hydrocracking process.

\section{ACKNOWLEDGMENTS}

The authors thank Yoann Levaque for helping in assembling the IR-ATR setup. Labex EMC3, ANR and FEDER are also acknowledged for the PhD grant of IK and the financial support to the BIOCAR project. Authors thank Ecopetrol S.A. for funding the present work through the project AC2-5211770. The gentle collaboration of the SC3 work team from the GUANE platform at UIS is acknowledged. VGBM thanks VIE-UIS and Colciencias are also thanks for funding and for $\mathrm{PhD}$ grant of CMCC. The authors also thank Lille University Calculation center (CRI) partially funded by FEDER for CPU allocation. 


\section{REFERENCES}

[1] R. A. Santen, M. Neurock, Wiley-VCH 2006, 474.

[2] G. H. C. Prado, Y. Rao, A. de Klerk, Energy Fuels 2017, 31, 14-36.

[3] M. Argyle, C. Bartholomew, Catalysts 2015, 5, 145-269.

[4] C. M. Celis-Cornejo, D. J. Pérez-Martínez, J. A. Orrego-Ruiz, V. G. BaldovinoMedrano, Energy Fuels 2018, 32, 8715-8726.

[5] J. K. Minderhoud, J. A. R. van Veen, Fuel Process. Technol. 1993, 35, 87-110.

[6] C. M. Fu, A. M. Schaffer, Ind. Eng. Chem. Prod. Res. Dev. 1985, 24, 68-75.

[7] G. Adamski, K. Dyrek, A. Kotarba, Z. Sojka, C. Sayag, G. Djéga-Mariadassou, Catal. Today 2004, 90, 115-119.

[8] P. Dufresne, A. Quesada, S. Mignard, Elsevier 1989, 301-315.

[9] M. Kobayashi, S. Togawa, K. Ishida, J. Jpn. Pet. Inst. 2007, 50, 44-52.

[10] M. Sau, K. Basak, U. Manna, M. Santra, R. P. Verma, Catal. Today 2005, 109, 112119.

[11] F. A. Barbosa, A. C. B. dos Santos, M. I. P. da Silva, A. M. Stumbo, Catal. Today 2004, 98, 109-113.

[12] E. Furimsky, F. E. Massoth, Catal. Today 1999, 52, 381-495.

[13] W. R. Pitt, D. M. Parry, B. G. Perry, C. R. Groom, J. Med. Chem. 2009, 52, 29522963.

[14] T. Nishida, H. Ida, Y. Kuninobu, M. Kanai, Nat. Commun. 2014, 5, 1-6.

[15] L. N. Obasi, U. S. Oruma, I. A. Al-Swaidan, P. Ramasami, C. J. Ezeorah, A. E. Ochonogor, Molecules 2017, 22, 153-163.

[16] D. Hédou, J. Godeau, N. Loaëc, L. Meijer, C. Fruit, T. Besson, Molecules 2016, 21, $578-596$.

[17] M. D. Altintop, Ö. D. Can, Ü. D. Demir Özkay, Z. A. Kaplancikli, Molecules 2016, 21, 1004-1013.

[18] S. Su, X. Zhou, G. Liao, P. Qi, L. Jin, Molecules 2017, 22, 64-80.

[19] D. V. Gopal, B. Srinivas, V. Durgakumari, M. Subrahmanyam, Appl. Catal., A 2002, $224,121-128$.

[20] M. Karthik, A. Tripathi, N. Gupta, M. Palanichamy, V. Murugesan, Catal. Commun. 2004, 5, 371-375.

[21] M. W. Roomi, S. F. MacDonald, Can. J. Chem. 1969, 48, 139-143.

[22] X. Zhao, Y. Jia, J. Li, R. Dong, J. Zhang, C. Ma, H. Wang, Y. Rui, X. Jiang, ACS Appl. Mater. Interfaces 2018, 10, 29398-29406.

[23] F. Thibault-Starzyk, F. Maugé, Wiley 2012, Chapter 1, 1-48.

[24] J. Ryczkowski, Catal. Today 2001, 68, 263-381.

[25] Pa. Meulen, R. F. Mann, J. Am. Chem. Soc. 1931, 53, 451-453.

[26] J.-M. Andanson, A. Baiker, Chem. Soc. Rev. 2010, 39, 4571-4584. 
1 [27] D. Rivera, J. M. Harris, Langmuir 2001, 17, 5527-5536.

2 [28] A. Davantès, D. Costa, B. Sallman, S. Rakshit, G. Lefèvre, J. Phys. Chem. C 2017, 3 $121,324-332$.

[29] I. A. Mudunkotuwa, A. A. Minshid, V. H. Grassian, Analyst 2014, 139, 870-881.

[30] B. Panella, A. Vargas, D. Ferri, A. Baiker, Chem. Mater. 2009, 21, 4316-4322.

[31] K. Grabow, U. Bentrup, ACS Catal. 2014, 4, 2153-2164.

[32] M. Chen, N. Maeda, A. Baiker, J. Huang, ACS Catal. 2012, 2, 2007-2013.

[33] C. Keresszegi, D. Ferri, T. Mallat, A. Baiker, J. Phys. Chem. B 2005, 109, 958-967.

[34] A. J. Wain, M. A. O’Connell, G. A. Attard, ACS Catal. 2018, 8, 3561-3570.

[35] D. Ferri, T. Bürgi, A. Baiker, J. Phys. Chem. B 2001, 105, 3187-3195.

[36] J. E. Pander, M. F. Baruch, A. B. Bocarsly, ACS Catal. 2016, 6, 7824-7833.

[37] M. F. Baruch, J. E. Pander, J. L. White, A. B. Bocarsly, ACS Catal. 2015, 5, 31483156.

[38] N. S. Gould, B. Xu, ACS Catal. 2018, 8, 8699-8708.

[39] J. Lomratsiri, M. Probst, J. Limtrakul, J. Mol. Graphics Modell. 2006, 25, 219-225.

[40] C. Liu, G. Li, E. J. M. Hensen, E. A. Pidko, J. Catal. 2016, 344, 570-577.

[41] J. Meeprasert, S. Jungsuttiwong, S. Namuangruk, Microporous Mesoporous Mater. 2013, 175, 99-106.

[42] M. Castella Ventura, E. Kassab, Y. Akacem, J. Phys. Chem. C 2008, 112, 1904519054.

[43] M. Grün, K. K. Unger, A. Matsumoto, K. Tsutsumi, Microporous Mesoporous Mater. 1999, 27, 207-216.

[44] S. Brunauer, P. H. Emmett, E. Teller, J. Am. Chem. Soc. 1938, 60, 309-319.

[45] M. Kruk, M. Jaroniec, C. H. Ko, R. Ryoo, Chem. Mater. 2000, 12, 1961-1968.

[46] M. Maache, A. Janin, J. C. Lavalley, E. Benazzi, Zeolites 1995, 15, 507-516.

[47] S. Chibani, M. Chebbi, S. Lebègue, T. Bučko, M. Badawi, J. Chem. Phys. 2016, $144,244705-244714$.

[48] J. Hafner, L. Benco, T. Bučko, Top. Catal. 2006, 37, 41-54.

[49] T. Barzetti, E. Selli, D. Moscotti, L. Forni, J. Chem. Soc., Faraday Trans. 1996, 92, 1401.

[50] C. Liu, I. Tranca, R. A. van Santen, E. J. M. Hensen, E. A. Pidko, J. Phys. Chem. C 2017, 121, 23520-23530.

[51] G. Kresse, J. Hafner, Phys. Rev. B 1993, 48, 13115-13118.

[52] G. Kresse, J. Hafner, Phys. Rev. B 1994, 49, 14251-14269.

[53] G. Kresse, J. Furthmüller, Comput. Mater. Sci. 1996, 6, 15-50.

[54] G. Kresse, D. Joubert, Phys. Rev. B 1999, 59, 1758-1775.

[55] E. P. Hessou, W. G. Kanhounnon, D. Rocca, H. Monnier, C. Vallières, S. Lebègue, M. Badawi, Theor. Chem. Acc. 2018, 137, 161-172. 
1 [56] J. P. Perdew, K. Burke, M. Ernzerhof, Phys. Rev. Lett. 1996, 77, 3865-3868.

2 [57] S. Grimme, S. Ehrlich, L. Goerigk, J. Comput. Chem. 2011, 32, 1456-1465.

3 [58] X. Rozanska, R. A. van Santen, F. Hutschka, J. Hafner, J. Am. Chem. Soc. 2001, $123,7655-7667$.

5

6

7

8

9

[59] C. M. Celis-Cornejo, M. M. Garnica Mantilla, V. G. Baldovino-Medrano, G. E. Ramírez-Caballero, J. Phys.: Conf. Ser. 2016, 743, 12010-12016.

[60] T. Demuth, J. Hafner, L. Benco, H. Toulhoat, J. Phys. Chem. B 2000, 104, 45934607.

[61] T. Bucko, L. Benco, Th. Demuth, J. Hafner, J. Chem. Phys. 2002, 117, 7295-7305.

[62] K. R. F. Somers, E. S. Kryachko, A. Ceulemans, Chem. Phys. 2004, 301, 61-79.

[63] I. Khalil, H. Jabraoui, G. Maurin, S. Lebègue, M. Badawi, K. Thomas, F. Maugé, J. Phys. Chem. C 2018, 122, 26419-26429.

[64] R. López-Fonseca, J. I. Gutiérrez-Ortiz, M. A. Gutiérrez-Ortiz, J. R. GonzálezVelasco, J. Catal. 2002, 209, 145-150.

[65] I. Fornefett, D. Rabet, C. Buttersack, K. Buchholz, Green Chem. 2016, 18, 33783388.

[66] I. Khalil, K. Thomas, H. Jabraoui, P. Bazin, F. Maugé, J. Hazard. Mater. 2019, Just accepted.

[67] J. N. Kondo, R. Nishitani, E. Yoda, T. Yokoi, T. Tatsumi, K. Domen, Phys. Chem. Chem. Phys. 2010, 12, 11576.

[68] G. Poncelet, J. Catal. 1978, 52, 321-331.

[69] T. K. Phung, M. M. Carnasciali, E. Finocchio, G. Busca, Appl. Catal., A 2014, 470, $72-80$.

[70] H. Jabraoui, I. Khalil, S. Lébegue, M. Badawi, Mol. Syst. Des. Eng. 2019, 4, 882892.

[71] S. Khabtou, T. Chevreau, J. C. Lavalley, Microporous Mater. 1994, 3, 133-148.

[72] L. M. Parker, D. M. Bibby, G. R. Burnst, J. Chem. Soc., Faraday Trans. 1991, 87, 3319-3323.

[73] E. Spinner, J. Chem. Soc. 1963, 3870-3873.

[74] E. B. Wilson, Phys. Rev. 1934, 45, 706-714.

[75] R. Ferwerda, J. H. van der Maas, F. B. van Duijneveldt, J. Mol. Catal. A: Chem. 1996, 104, 319-328.

[76] L. Kubelkova, J. Kotrla, J. Florian, J. Phys. Chem. 1995, 99, 10285-10293.

[77] G. C. Laredo, S. Leyva, R. Alvarez, M. T. Mares, J. Castillo, J. L. Cano, Fuel 2002, 81, 1341-1350.

[78] M. A. Larrubia, A. Gutièrrez-Alejandre, J. Ramìrez, G. Busca, Appl. Catal., A 2002, 224, 167-178. 